\title{
Sonographic Evaluation of Nodules Newly Detected in the Neck After Thyroidectomy: Suture Granuloma Versus Recurrent Carcinoma
}

\section{(요 (요 $\ominus$}

Authors

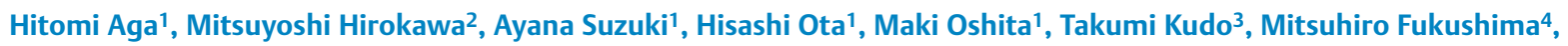
Kaoru Kobayashi ${ }^{4}$, Akira Miyauchi ${ }^{4}$

Affiliations

1 Kuma Hospital, Department of Clinical Laboratory, Kobe, Japan

2 Kuma Hospital, Department of Diagnostic Pathology and Cytology, Kobe, Japan

3 Kuma Hospital, Department of Internal Medicine, Kobe, Japan

4 Kuma Hospital, Department of Surgery, Kobe, Japan

Key words

Thyroid, Suture granuloma, Recurrent carcinoma,

Ultrasound, Thyroidectomy

received $\quad 30.05 .2018$

revised $\quad 05.09 .2018$

accepted 10.09 .2018

Bibliography

DOI https://doi.org/10.1055/a-0749-8688

Ultrasound Int Open 2018; 4: E124-E130

(c) Georg Thieme Verlag KG Stuttgart · New York

ISSN 2199-7152

Correspondence

Ms. Hitomi Aga

Kuma Hospital

Department of Clinical Laboratory

8-2-35, Shimoyamate-dori

Chuo-ku

650-0011 Kobe

Japan

Tel.: +81/78/371 3721, aga@m.kuma-h.or.jp

\section{ABSTRACT}

Purpose This study aimed to clarify the sonographic features of suture granuloma and recurrent carcinoma newly detected after thyroidectomy.

Materials and Methods We retrospectively analyzed ultrasound reports with images of 25 cases of suture granuloma and 18 cases of recurrent carcinoma that newly appeared in the resected area after thyroidectomy in our institution.

Results Both suture granulomas and recurrent carcinomas more frequently exhibited multiple lesions rather than solitary lesions. Suture granulomas tended to appear in the more superficial areas than the carotid artery, while recurrent carcinomas were more common between the trachea and carotid artery. A total of 10 of the 11 suture granulomas that we followed up decreased in size. Recurrent carcinomas showed irregular shape (55.6\%), taller-than-wide shape (38.9\%), low internal echogenicity ( $83.3 \%)$, and no punctate microcalcifications. By contrast, suture granulomas were fusiform in shape (56.0\%) and showed linear internal echo parallel to the tissue plane on the longitudinal scan (64.0\%). The vascular flow sign was mild to none in the majority of both lesions.

Conclusion Fusiform shape and linear internal echoes indicate suture granuloma, while irregular shape, taller-than-wide shape, and low echogenicity indicate recurrent carcinoma. Given that the clinical management of suture granuloma differs from that of recurrent carcinoma, it is important to distinguish between these two lesions.

\section{Introduction}

Ultrasonography (US) plays an important role not only in detecting thyroid nodules preoperatively, but also in detecting recurrent thyroid carcinoma in the neck postoperatively [1-5]. US should be performed at 6 to 12 months after surgery for thyroid carcinoma to evaluate the thyroid bed and cervical nodal compartments and then every 6 months, depending on the patient's risk for recurrent disease and serum thyroglobulin status [1]. Postoperatively, suture granulomas are frequently confused with recurrent carcinomas [2,6-9]. Suture granulomas are benign granulomatous lesions occurring after a surgical intervention and a foreign-body reaction for retained suture materials [7, 10-13]. The lesions usually develop slowly after the intervention and may become palpable and tender masses $[10,14]$. This study aimed to distinguish between the sonographic features of suture granuloma and recurrent carcinoma newly detected after thyroidectomy.

\section{Materials and Methods}

We reviewed cytology reports of 135 patients who underwent fine-needle aspiration cytology (FNAC) for nodules that newly ap- 


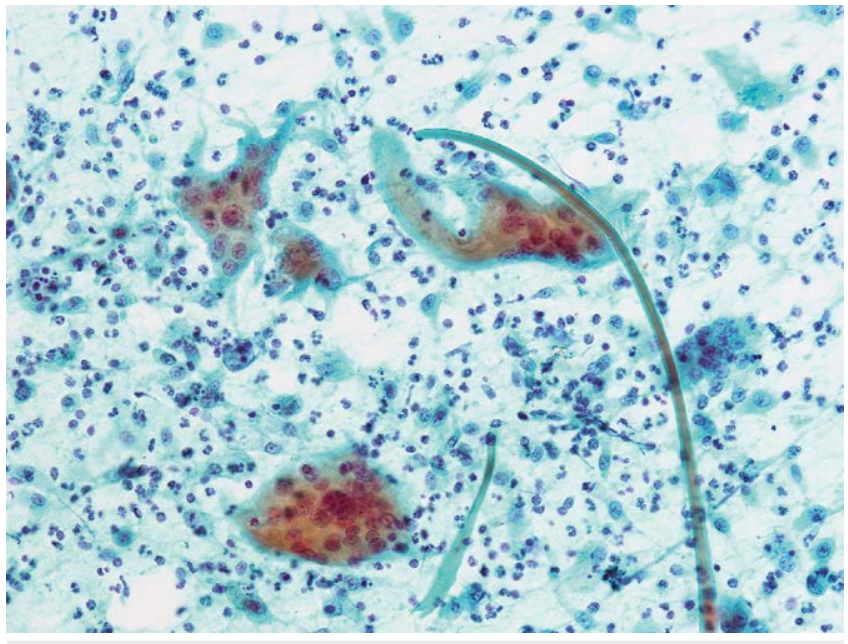

-Fig. 1 Foreign body granuloma. Multinucleated giant cells, histiocytes, neutrophils, and suture thread are mixed. (Aspiration cytology, Papanicolaou stain, $\times 200$ ). peared in the resected area after thyroidectomy in our institution between January 2006 and December 2016. We excluded the patients with the following lesions: 1 ) nodules that occurred in areas other than the surgical field and 2) nodules histologically confirmed to be nodal metastasis or needle tract implantation. Finally, $25 \mathrm{pa}$ tients with suture granuloma and 18 patients with recurrent carcinoma were analyzed for this study. Suture granuloma was diagnosed according to the presence of foreign body-type giant cells and no carcinoma cells in FNAC ( $\triangleright$ Fig. 1). Meanwhile, recurrent carcinoma was confirmed via FNAC. In patients with multiple nodules, we examined those which had undergone FNAC. US was performed using the APLIO 80 SSA-770A (Toshiba Medical Systems Co., Ltd., Otawara, Japan) or APLIO 500 TUS-A500 (Toshiba) with the PLT-805AT (Toshiba) or PLT-1005BT probe (Toshiba). We retrospectively analyzed the US reports with images that were obtained from the patients' medical records at Kuma Hospital. Statistical analysis was performed using Fisher's exact or Student's t tests. P-values $<0.05$ were considered significant. Written informed con-

- Table 1 Characteristics and clinical findings of the 25 patients with suture granulomas and 18 patients with recurrent carcinomas.

\begin{tabular}{|c|c|c|}
\hline & Suture granulomas & Recurrent carcinomas \\
\hline & $(n=25)$ & $(n=18)$ \\
\hline Sex (female/male) & $20 / 5$ & $14 / 4$ \\
\hline Mean age, years (range) & $54.9(32-76)$ & $69.9(42-86)$ \\
\hline \multicolumn{3}{|l|}{ Previous surgery } \\
\hline Lobectomy/total thyroidectomy & $8 / 17$ & $7 / 11$ \\
\hline \multicolumn{3}{|l|}{ Nodal dissection } \\
\hline None/central/central + lateral & $5 / 10 / 10$ & $1 / 1 / 16$ \\
\hline \multicolumn{3}{|l|}{ Histology of resected thyroid } \\
\hline Graves' disease & $1(4.0 \%)$ & $0(0 \%)$ \\
\hline Benign nodular goiter & $5(20.0 \%)$ & $0(0 \%)$ \\
\hline Papillary carcinoma & $18(72.0 \%)$ & $15(83.3 \%)$ \\
\hline Poorly differentiated carcinoma & $1(4.0 \%)$ & $2(11.1 \%)$ \\
\hline Anaplastic carcinoma & $0(0 \%)$ & $1(5.6 \%)$ \\
\hline \multicolumn{3}{|l|}{ Time from initial surgery to diagnosis (months) } \\
\hline \multirow[t]{2}{*}{ Mean (range) } & $58.5(3-281)$ & $95.4(4-439)$ \\
\hline & \multicolumn{2}{|c|}{$p<0.01$} \\
\hline$<12$ months & $5(20.0 \%)$ & $4(22.2 \%)$ \\
\hline 12 to 24 months & $5(20.0 \%)$ & $3(16.7 \%)$ \\
\hline$>24$ months & $15(60.0 \%)$ & $11(61.1 \%)$ \\
\hline \multicolumn{3}{|l|}{ Lesions } \\
\hline Solitary & $8(32.0 \%)$ & $7(38.9 \%)$ \\
\hline Multiple & $17(68.0 \%)$ & $11(61.1 \%)$ \\
\hline Thyroglobulin in needle wash-out fluid (ng/mL) & $(n=11)$ & $(n=10)$ \\
\hline Mean (range) & $\begin{array}{l}4.9(0-8.3) \\
\stackrel{L}{L}\end{array}$ & $1155.3(1.4-8000)$ \\
\hline & \multicolumn{2}{|c|}{$p<0.001$} \\
\hline \multirow[t]{2}{*}{$<10 \mathrm{ng} / \mathrm{mL}$} & $\begin{array}{c}11(100 \%) \\
L\end{array}$ & $2(20.0 \%)$ \\
\hline & \multicolumn{2}{|c|}{$p<0.001$} \\
\hline \multicolumn{3}{|l|}{ Diagnoses suspected via ultrasound } \\
\hline \multirow[t]{2}{*}{ Suture granuloma } & 14 (56.0\%) & $0(0 \%)$ \\
\hline & \multicolumn{2}{|c|}{$p<0.05$} \\
\hline \multirow[t]{2}{*}{ Carcinoma } & $5(20.0 \%)$ & $16(88.9 \%)$ \\
\hline & \multicolumn{2}{|c|}{$p<0.01$} \\
\hline Not described & $6(24.0 \%)$ & $2(11.0 \%)$ \\
\hline
\end{tabular}


sent was obtained from all patients, and the study design was approved by an institutional review board.

\section{Results}

The suture granuloma group comprised 20 women and 5 men with a mean age of 54.9 years. Meanwhile, the recurrent carcinoma group comprised 14 women and 4 men with a mean age of 69.9 years. The mean age was lower in the suture carcinoma group, but the difference was not significant. - Table 1 shows the clinical findings of the 25 suture granulomas and 18 recurrent carcinomas. Lobectomy and total thyroidectomy were performed in 8 and 17 patients with suture granulomas and in 7 and 11 patients with recurrent carcinomas, respectively. As regards nodal dissection, 10 patients with suture granulomas underwent central nodal dissection, and another 10 underwent central and lateral dissection. Meanwhile, 16 of the 17 nodal dissections in the patients with recurrent carcinomas were central and lateral dissections. In 6 (24.0\%) of the patients with suture granulomas, the surgery was due to benign conditions, including Graves' disease and benign nodular goiter.

The mean interval between initial surgeries and the diagnosis of suture granulomas was significantly shorter than that for recur- rent carcinomas ((58.5 months (range: 3-281 months) vs. 95.4 months (range: $4-439$ months), respectively; $p<0.01$ ). Multiple lesions were more frequent than solitary lesions in both suture granuloma and recurrent carcinoma. In 11 suture granulomas and 10 recurrent carcinomas, the thyroglobulin level was measured during FNAC using needle wash-out fluid with $0.5 \mathrm{~mL}$ saline. The mean thyroglobulin levels in the patients with suture granulomas (4.9 ng/ $\mathrm{mL}$ ) were significantly lower than in those with recurrent carcinomas $(1155.3 \mathrm{ng} / \mathrm{mL})(p<0.001)$. The thyroglobulin levels in all patients with suture granuloma was $<10 \mathrm{ng} / \mathrm{mL}$. Two recurrent carcinomas that showed a thyroglobulin level of $<10 \mathrm{ng} / \mathrm{mL}$ were poorly differentiated carcinoma and anaplastic carcinoma. A total of $16(88.9 \%)$ recurrent carcinomas were interpreted as recurrent carcinoma based on the original US reports, and there were no recurrent carcinomas interpreted as suture granulomas. 14 (56.0\%) and 5 (20.0\%) suture granulomas were interpreted as suture granuloma and recurrent carcinoma, respectively.

- Table 2 shows the location of suture granulomas and recurrent carcinomas. Of the 25 suture granulomas, 21 (84.0\%) appeared in the more superficial areas than the carotid artery. $8(32.0 \%)$ and $7(28.0 \%)$ suture granulomas appeared in front of the trachea ( $\vee$ Fig. $2 \mathbf{a}$ ) and in the more lateral areas than the carot-

- Table 2 Location of the 25 suture granulomas and 18 recurrent carcinomas.

Suture granuloma $(n=25)$

\begin{tabular}{|c|c|c|c|c|}
\hline \multirow[t]{2}{*}{ Horizontal } & Pretrachea & $\begin{array}{l}\text { Between the trachea and } \\
\text { carotid artery }\end{array}$ & Carotid artery & $\begin{array}{l}\text { Lateral to the carotid } \\
\text { artery }\end{array}$ \\
\hline & $8(32.0 \%)$ & $9(36.0 \%)$ & $1(4.0 \%)$ & $7(28.0 \%)$ \\
\hline \multirow[t]{2}{*}{ Vertical } & $\begin{array}{l}\text { Subcutaneous to the anterior } \\
\text { trachea }\end{array}$ & $\begin{array}{l}\text { Anterior to the carotid } \\
\text { artery }\end{array}$ & Carotid artery & $\begin{array}{l}\text { Dorsal to the carotid } \\
\text { artery }\end{array}$ \\
\hline & $14(56.0 \%)$ & $7(28.0 \%)$ & $4(16.0 \%)$ & $0(0 \%)$ \\
\hline \multicolumn{5}{|c|}{ Recurrent carcinoma $(n=18)$} \\
\hline \multirow[t]{2}{*}{ Horizontal } & Pretrachea & $\begin{array}{l}\text { Between the trachea and } \\
\text { carotid artery }\end{array}$ & Carotid artery & $\begin{array}{l}\text { Lateral to the carotid } \\
\text { artery }\end{array}$ \\
\hline & $0(0 \%)$ & $17(94.4 \%)$ & $1(5.6 \%)$ & $0(0 \%)$ \\
\hline \multirow[t]{2}{*}{ Vertical } & $\begin{array}{l}\text { Subcutaneous to the anterior } \\
\text { trachea }\end{array}$ & $\begin{array}{l}\text { Anterior to the carotid } \\
\text { artery }\end{array}$ & Carotid artery & $\begin{array}{l}\text { Dorsal to the carotid } \\
\text { artery }\end{array}$ \\
\hline & $0(0 \%)$ & $5(27.8 \%)$ & $9(50.0 \%)$ & $4(22.2 \%)$ \\
\hline
\end{tabular}
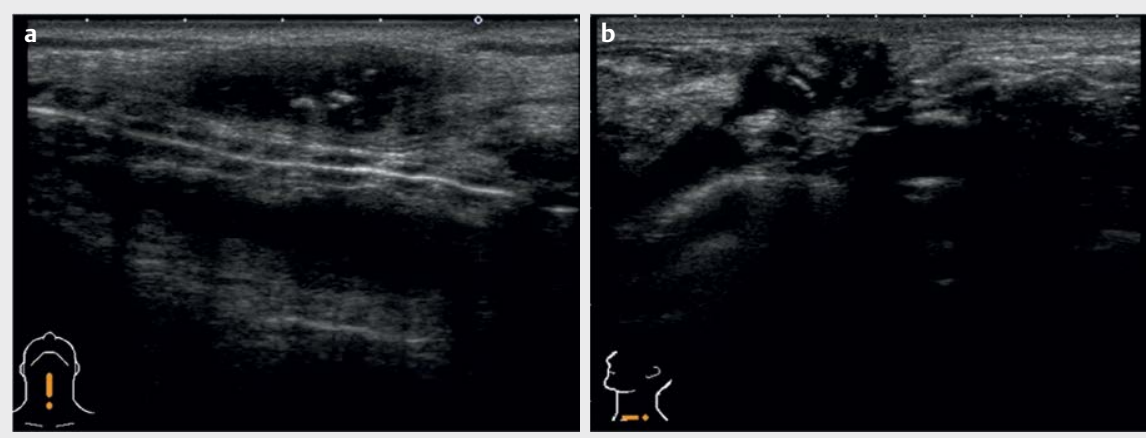

Fig. 2 Suture granuloma. Nodules A and B existed in front of the trachea and in the more lateral area from the carotid artery, respectively. A linear internal echo parallel to the tissue plane was present (a B-mode, longitudinal view. b B-mode, horizontal view). 

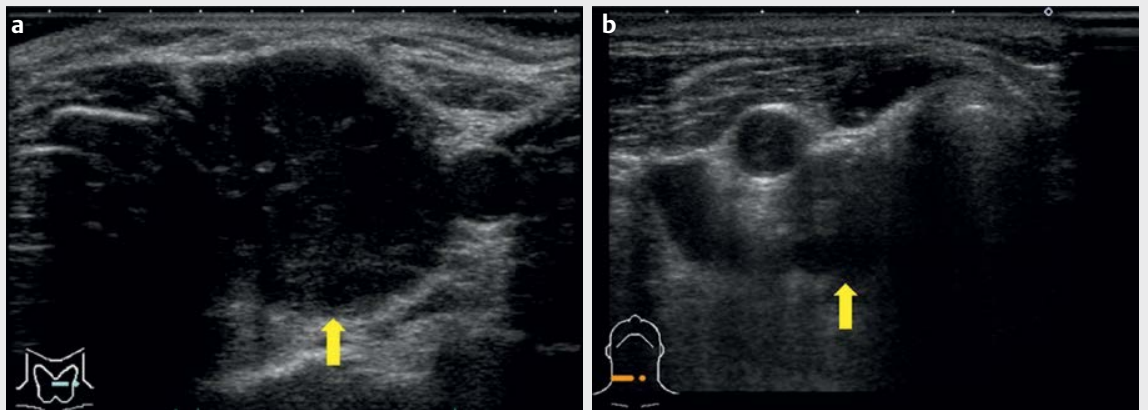

- Fig. 3 Recurrent papillary thyroid carcinoma. Nodules A and B existed between the trachea and left carotid artery and in deeper areas (arrows) than the carotid artery, respectively. (a B-mode, horizontal view. b B-mode, horizontal view)

- Table 3 Sonographic comparison between suture granulomas and recurrent carcinomas after thyroidectomy

\begin{tabular}{|c|c|c|}
\hline & $\begin{array}{c}\text { Suture } \\
\text { granuloma }\end{array}$ & $\begin{array}{l}\text { Recurrent } \\
\text { carcinoma }\end{array}$ \\
\hline & $(n=25)$ & $(n=18)$ \\
\hline \multicolumn{3}{|l|}{ Shape } \\
\hline Round-ovoid & $6(24.0 \%)$ & $5(27.8 \%)$ \\
\hline Fusiform & $14(56.0 \%)$ & $3(16.7 \%)$ \\
\hline \multirow[t]{2}{*}{ Irregular } & $4(16.0 \%)$ & $10(55.6 \%)$ \\
\hline & \multicolumn{2}{|c|}{$p<0.01$} \\
\hline Mean size, mm (range) & $14.2(5-35)$ & $23.6(7-42)$ \\
\hline Solid & $25(100 \%)$ & $17(94.4 \%)$ \\
\hline Cyst & 0 & 1 \\
\hline Taller-than-wide shape & $3 / 24(12.5 \%)$ & $7(38.9 \%)$ \\
\hline III-defined margin & $21(84.0 \%)$ & $16(88.9 \%)$ \\
\hline Marginal sonolucent rim & $0(0 \%)$ & $0(0 \%)$ \\
\hline \multicolumn{3}{|l|}{ Echogenicity } \\
\hline Hyperechoic & $0(0 \%)$ & $0(0 \%)$ \\
\hline Isoechoic & $14(56.0 \%)$ & $3(16.7 \%)$ \\
\hline \multirow[t]{2}{*}{ Hypoechoic } & $11(44.0 \%)$ & $15(83.3 \%)$ \\
\hline & \multicolumn{2}{|c|}{$\mathrm{p}<0.05$} \\
\hline \multirow[t]{2}{*}{ Echogenic dots (linear internal echo) } & $16(64.0 \%)$ & $0(0 \%)$ \\
\hline & \multicolumn{2}{|c|}{$p<0.001$} \\
\hline Single & 3 & 0 \\
\hline Paired & 2 & 0 \\
\hline Multiple & 11 & 0 \\
\hline Punctate microcalcifications & 1 & 0 \\
\hline $\begin{array}{l}\text { Echogenic lesion with posterior } \\
\text { acoustic shadowing }\end{array}$ & 5 & 3 \\
\hline \multicolumn{3}{|l|}{ Vascularity } \\
\hline None & $19(76.0 \%)$ & $11(61.1 \%)$ \\
\hline Mild & $4(16.0 \%)$ & $5(27.7 \%)$ \\
\hline Moderate & $2(8.0 \%)$ & $2(11.1 \%)$ \\
\hline Severe & $0(0 \%)$ & $0(0 \%)$ \\
\hline
\end{tabular}

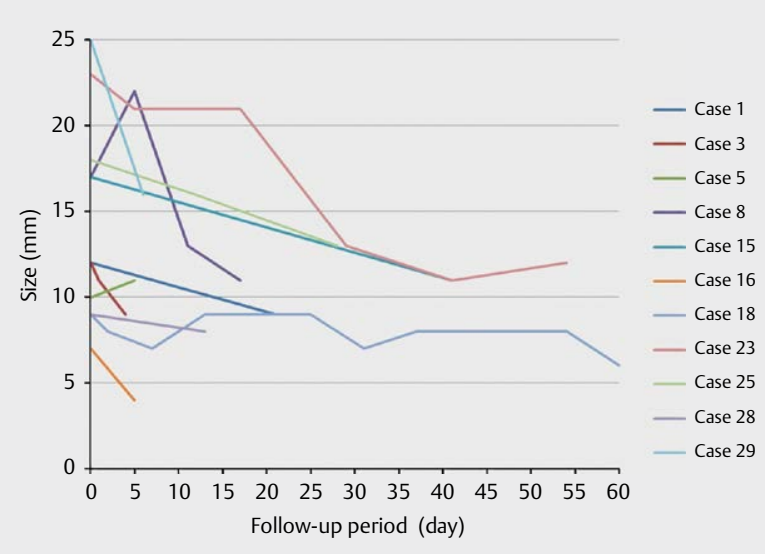

- Fig. 4 Trends in size of suture granuloma during follow-up.

id artery ( $\triangleright$ Fig. $\mathbf{2 b}$ ), respectively. However, recurrent carcinomas did not appear in these areas. Most of them (94.4\%) appeared between the trachea and carotid artery ( $>$ Fig. $3 a) .4(22.2 \%$ ) recurrent carcinomas appeared in deeper areas than the carotid artery ( $\triangleright$ Fig. 3b), while suture granulomas were not observed in this area. The location of suture granulomas was significantly different than that of recurrent carcinomas $(p<0.001)$.

- Table 3 shows the sonographic comparison between suture granulomas and recurrent carcinomas. All nodules were solid except for one recurrent carcinoma that was cystic. The sizes of suture granulomas ranged from $5 \mathrm{~mm}$ to $35 \mathrm{~mm}$, while those of recurrent carcinomas ranged from $7 \mathrm{~mm}$ to $42 \mathrm{~mm}$. There was no significant difference in the sizes. Among the 11 suture granulomas that could be followed (4 to 60 months), the sizes were decreased in 10 cases ( $\triangleright \mathbf{F i g . ~} \mathbf{4 , 5}) .10$ recurrent carcinomas were irregular in shape ( $\triangleright$ Fig. 6), and the percentage of irregularly shaped carcinomas was significantly higher in recurrent carcinomas than that in suture granulomas ( $55.6 \%$ vs. $16.0 \%$; $p<0.01$ ). Meanwhile, $56.0 \%$ of the suture granulomas were fusiform in shape ( $\mathbf{F i g} . \mathbf{5}$ ).

The majority of the nodules in both lesions had predominantly ill-defined margins. The taller-than-wide shape (ratio of $>1$ of the anteroposterior diameter to the transverse diameter) tended to be more common in recurrent carcinomas $(38.9 \%)$ than in suture 

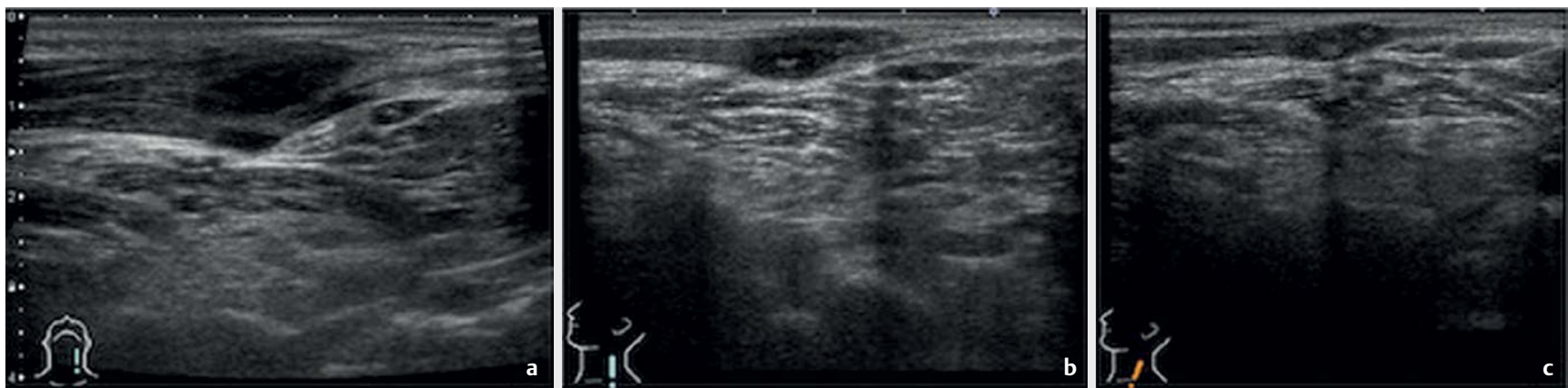

-Fig. 5 Suture granuloma (Case 25). The nodule measured $18 \times 6 \mathrm{~mm}$ at presentation a. After 12 and 28 months, it reduced to $16 \times 5 \mathrm{~mm} \mathbf{b}$ and $13 \times 4 \mathrm{~mm}$ c, respectively. Each nodule was fusiform in shape (a: B-mode, longitudinal view. b B-mode, longitudinal view. c B-mode, longitudinal view.).

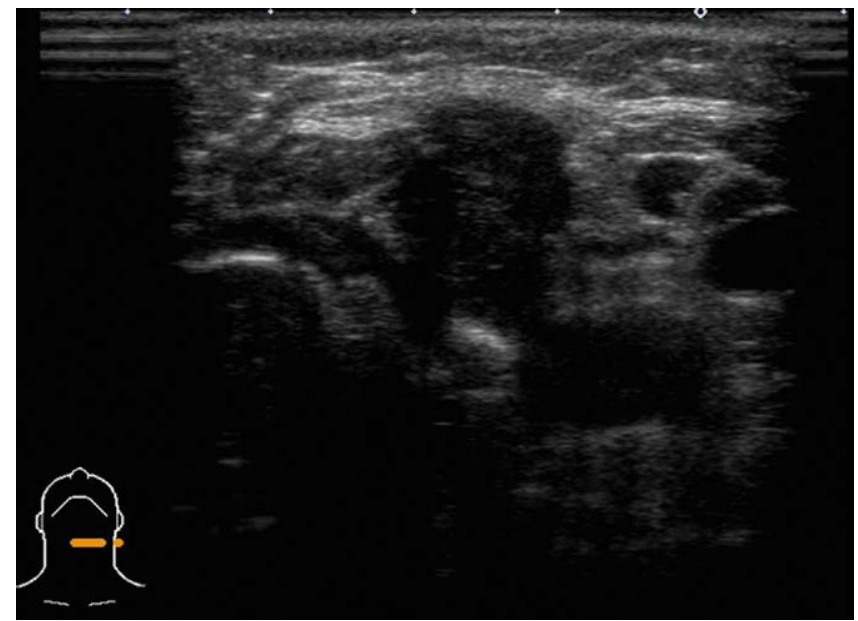

Fig. 6 Recurrent papillary thyroid carcinoma. The nodule was irregular in shape and the anteroposterior diameterto-the transverse diameter ratio was $>1.0$ (B-mode, horizontal view).

granulomas (12.5\%) (\Fig. 6). Internal echogenicity was low in $11(44.0 \%)$ suture granulomas and 15 (83.3\%) recurrent carcinomas $(p<0.05)$. Echogenic dots were observed in $64.0 \%$ of suture granulomas and not in recurrent carcinomas $(p<0.001)$ ( $\triangleright$ Fig. 7). The dots were single, paired, and multiple in 3, 2, and 11 lesions, respectively. They were occasionally fused. The structure was observed as a linear internal echo parallel to the tissue plane on the longitudinal scan ( $>$ Fig. 2). Punctate microcalcifications were not observed in recurrent carcinomas. An echogenic lesion with posterior acoustic shadowing was seen in 5 suture granulomas and 3 recurrent carcinomas ( $\mathbf{F i g} \mathbf{8}$ ). There was a mild to no vascular flow sign in both lesions.

\section{Discussion}

Various nodules including recurrent thyroid carcinomas and benign lesions may newly appear on follow-up in patients who underwent thyroidectomy [4, 5, 8]. Although papillary thyroid carcinoma (PTC) as a relatively indolent, locoregional recurrence is common [1]. Up to $20 \%$ of patients with well-differentiated carcinoma develop lo-

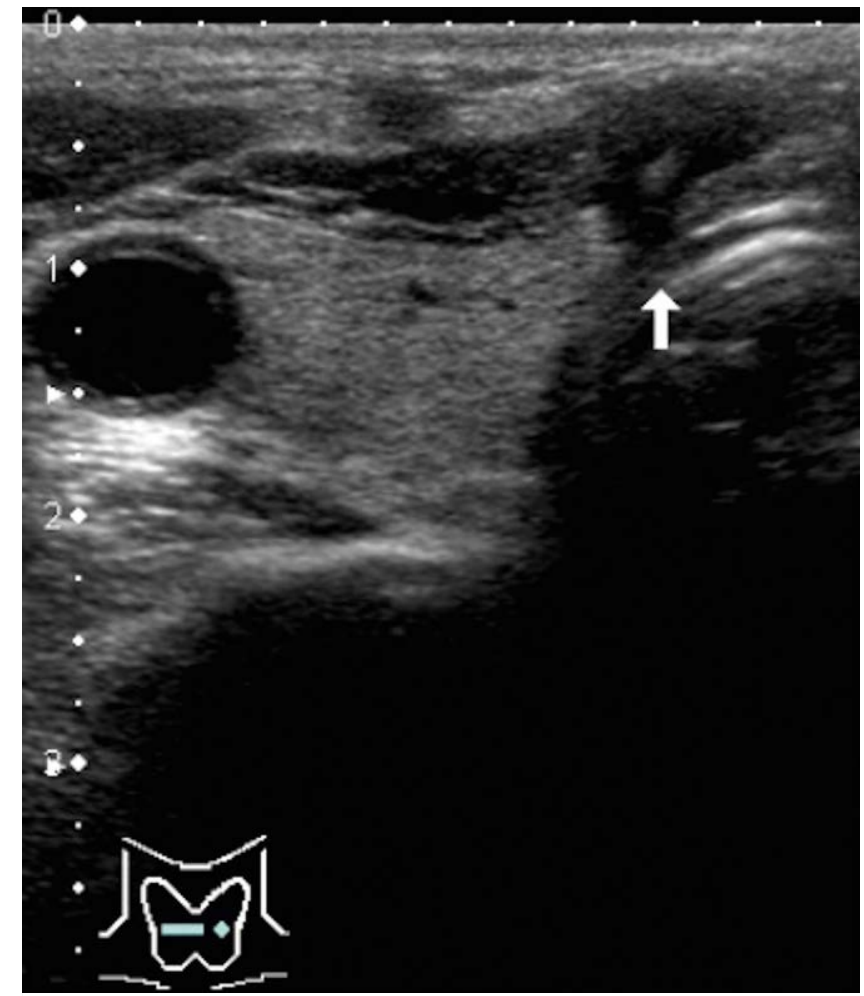

-Fig. 7 Suture granuloma. The hypoechoic nodule (arrow) was irregular in shape, had an ill-defined margin, and showed an echogenic dot (B-mode, horizontal view).

coregional recurrence in the thyroidectomy bed $[15,16]$. US is a very sensitive modality for detecting such nodules [1]. Lee et al. reported that the rate of malignancy was significantly higher in nodules with a marginal irregularity, microcalcifications, and a shape not parallel to the surrounding tissue plane [4]. Kamaya et al. concluded that hypoechoic thyroidectomy bed lesions with internal vascularity and a size greater than $6 \mathrm{~mm}$ are highly sensitive in predicting recurrence [3]. They reported that $100 \%$ of the lesions with recurrence had detectable internal vascularity on color Doppler or power Doppler imaging [3]. Taller-than-wide in shape was also a feature of recurrent carcinomas [7, 17]. 


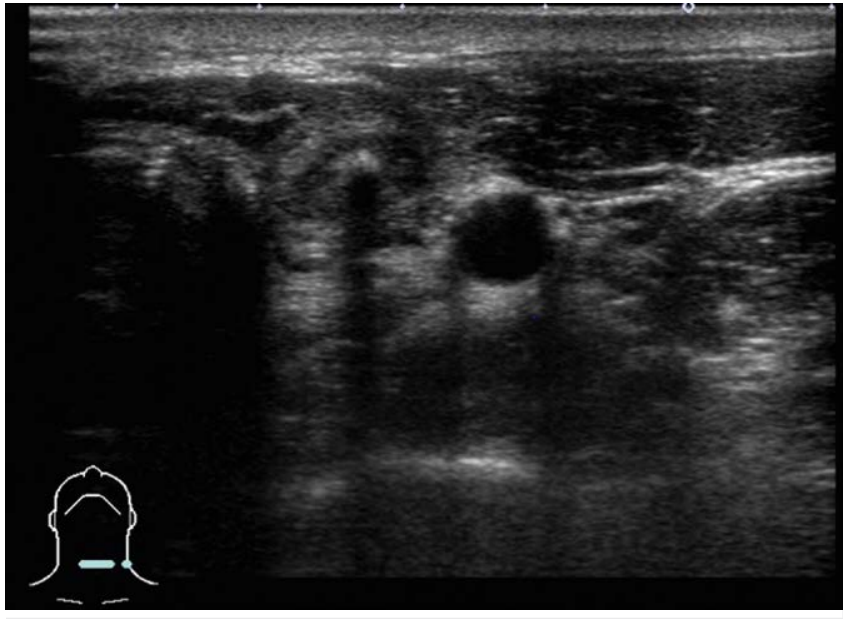

-Fig. 8 Suture granuloma. An echogenic lesion with posterior acoustic shadowing was seen (B-mode, horizontal view).

The US findings of recurrent carcinomas in our study were consistent with the above findings except for internal vascularity and microcalcifications. In our study, $61.1 \%$ and $100 \%$ of recurrent carcinomas did not have a vascular flow sign and punctate microcalcifications, respectively. Punctate microcalcifications are found in association with tumor necrosis within lymphatic spaces, and their incidence in microcarcinomas is lower in larger PTCs [18]. Therefore, their absence in recurrent carcinomas may be related to poor lymphatic invasion or small size. We concluded that vascular flow sign and punctate microcalcifications are not major predictors of malignancy in recurrent carcinoma.

Thyroglobulin measurement using needle wash-out fluid is a reliable technique for diagnosing recurrent carcinoma [19]. However, the thyroglobulin level is not elevated in cases of poorly differentiated carcinoma or anaplastic thyroid carcinoma [20,21]. As expected, in our study, the number of thyroglobulin measurements performed was not significantly different between those with recurrent poorly differentiated carcinoma and anaplastic carcinoma.

Suture granuloma is a rare complication of thyroidectomy associated with the use of non-absorbable suture materials [7-11]. The characteristic US findings of suture granuloma are ill- or well-defined, heterogeneous, irregular, hypo- to isoechoic lesions with linear internal echoes parallel to the surrounding tissue plane on the longitudinal section $[4-6,10,11]$. The linear internal echoes appear as echogenic dots on the transverse section, are larger than $1 \mathrm{~mm}$ in diameter, and are located centrally or paracentrally $[8,11]$. The internal echoes are frequently paired [8, 11]. In 2016, we stopped using silk thread to avoid the occurrence of suture granuloma. In our study, echogenic dots were less frequently observed (64.0\%) compared with previously reported cases (85.7\%). In addition, $68.8 \%$ of the nodules with echogenic dots exhibited more than two dots.

It is not easy to distinguish between suture granuloma and recurrent carcinoma on US [8]. In this study, we compared the US findings of suture granulomas and recurrent carcinomas. A fusiform shape and linear internal echoes indicate suture granuloma. By contrast, an irregular shape, taller-than-wide shape, and low echogenicity indicated recurrent carcinoma. Contrary to our ex- pectation, we did not observe the punctate microcalcification characteristic of PTC in recurrent carcinomas. These findings indicate that punctate microcalcification is not useful to distinguish the two conditions. Meanwhile, the location of the lesions may be helpful. A total of $84.0 \%$ of suture granulomas and $94.4 \%$ of recurrent carcinomas appeared in the more superficial areas than the carotid artery and between the trachea and carotid artery, respectively. Recurrent carcinomas did not appear in front of the trachea or in the more lateral areas than the carotid artery, while suture granulomas appeared in deeper areas than the carotid artery. However, we did not evaluate the developmental mechanism of these two conditions. Suture granulomas can resolve spontaneously $[8,11]$. Kim et al. reported that 9 of 10 suture granulomas disappeared or decreased in size during follow-up [11]. Similarly, 10 of the 11 suture granulomas that we could follow up decreased in size.

Recently, it has also been reported that semiquantitative elastosonography is a valuable tool in the characterization of thyroid nodules; it seems to be more sensitive than contrast-enhanced ultrasound [22-26]. However, we have not performed this technique in this study because such new techniques are not popular in Japan. In the future, we expect that such techniques will be able to distinguish between suture granuloma and recurrent carcinoma with more accuracy.

In conclusion, we showed that a fusiform shape and linear internal echoes indicate suture granuloma, whereas an irregular shape, taller-than-wide shape, and low echogenicity indicate recurrent carcinoma. Moreover, the location may be useful in distinguishing between these two conditions, while punctate microcalcification is not. It is important to distinguish between suture granuloma and recurrent carcinoma because their treatment differs. If a definite diagnosis of suture granuloma is established, further examination and treatment might be unnecessary. However, we recommend that suture granulomas be differentiated from recurrent carcinomas through a combination of US, FNAC, and thyroglobulin measurement using needle wash-out fluid.

\section{Conflict of Interest}

The authors declare no conflict of interest.

\section{References}

[1] Haugen BR, Alexander EK, Bible KC, Doherty GM, Mandel SJ, Nikiforov YE, Pacini F, Randolph GW, Sawka AM, Schlumberger M, Schuff KG, Sherman SI, Sosa JA, Steward DL, Tuttle RM, Wartofsky L. 2015 American Thyroid Association Management Guidelines for Adult Patients with Thyroid Nodules and Differentiated Thyroid Cancer: The American Thyroid Association Guidelines Task Force on Thyroid Nodules and Differentiated Thyroid Cancer. Thyroid 2016; 26: 1-133

[2] Moslehi M, Assadi M. Contribution of ultrasound examination in the detection of neck recurrence in low-risk differentiated thyroid carcinoma patients at first follow-up visits. Nuclear Med Rev 2014; 17 : 3-6

[3] Kamaya A, Gross M, Akatsu H, Jeffrey RB. Recurrence in the thyroidectomy bed: Sonographic findings. Am J Roentgenol 2011; 196: 66-70 
[4] Lee JH, Lee HK, Lee DH, Choi CG, Gong G, Shong YK, Kim S]. Ultrasonographic findings of a newly detected nodule on the thyroid bed in postoperative patients for thyroid carcinoma: Correlation with the results of ultrasonography-guided fine-needle aspiration biopsy. Clin Imaging 2007; 31: 109-113

[5] Zaheer S, Tan A, Ang ES, Loke KS, Kao YH, Goh A, Wong WY. Post-thyroidectomy neck ultrasonography in patients with thyroid cancer and a review of the literature. Singapore Med J 2014; 55 : $343-350$

[6] Kim HR, Hong HS, Lee EH, Lee MH, Park JM, Kwak J], Lee SW. Ultrasonographic findings of foreign-body granulomas after endoscopic thyroidectomy via an axillo-breast approach. J Korean Soc Radiol 2012; 66: 507-517

[7] Chung YE, Kim EK, Kim M], Yun M, Hong SW. Suture granuloma mimicking recurrent thyroid carcinoma on ultrasonography. Yonsei Med J 2006; 31: 748-751

[8] Ko MS, Lee JH, Shong YK, Gong GY, Baek JH. Normal and abnormal sonographic findings at the thyroidectomy sites in postoperative patients with thyroid malignancy. Am J Roentgenol 2010; 194 : 1596-1609

[9] Shin JH, Han BK, Ko EY, Kang SS. Sonographic findings in the surgical bed after thyroidectomy: Comparison of recurrent tumors and nonrecurrent lesions. J Ultrasound Med 2007; 26: 1359-1366

[10] Rettenbacher T, Macheiner P, Hollerweger A, Gritzmann N, Weismann C, Todoroff $B$. Suture granulomas: sonography enables a correct preoperative diagnosis. Ultrasound Med Biol 2001; 27: 343-350

[11] Kim JH, Lee JH, Shong YK, Hong SJ, Ko MS, Lee DH, Choi CG, Kim SJ. Ultrasound features of suture granulomas in the thyroid bed after thyroidectomy for papillary thyroid carcinoma with an emphasis on their differentiation from locally recurrent thyroid carcinomas. Ultrasound Med Biol 2009; 35: 1452-1457

[12] Rosenberg N, Moolten SE, Vroman L. Tissue reactions to waxes derived from spool cotton; Possible etiologic relation to suture granulomas and suture extrusion. Arch Surg 1950; 60: 363-371

[13] Rosenberg D, Schechtmann M. Granuloma of the stomach caused by a foreign body (cotton thread suture). Rev Paul Med 1963; 62: 325-332

[14] Augustin G, Korolija D, Skegro M, Jakic-Razumovic J. Suture granuloma of the abdominal wall with intra-abdominal extension 12 years after open appendectomy. World J Gastroenterol 2009; 28: 4083-4086

[15] Shulumberger M]. Papillary and follicular thyroid carcinoma. N Engl ] Med 1998; 338: 297-306

[16] Mazzaferri EL. An overview of the management of papillary and follicular thyroid carcinoma. Thyroid 1999; 9: 421-427

[17] Titton RL, Gervais DA, Boland GW, Maher MM, Mueller PR. Sonography and sonographically guided fine-needle aspiration biopsy of the thyroid gland: indications and techniques, pearls and pitfalls. Am J Roentgenol 2003; 181: 267-271

[18] Oh EM, Chung YS, Song WJ, Lee YD. The pattern and significance of the calcifications of papillary thyroid microcarcinoma presented in preoperative neck ultrasonography. Ann Surg Treat Res 2014; 86: $115-121$
[19] Baskin H]. Detection of recurrent papillary thyroid carcinoma by thyroglobulin assessment in the needle washout after fine-needle aspiration of suspicious lymph nodes. Thyroid 2004; 14: 959-963

[20] Achille G, Garrisi VM, Russo S, Guastamacchia E, Giagulli VA, Schirosi L, Daniele A, Tufaro A, Cafagna V, Centrone M, Simone G, Abbate I, Triggiani V. Thyroglobulin determination in fine needle aspiration biopsy washout of suspicious lymph nodes in thyroid carcinoma follow up. Endocr Metab Immune Disord Drug Targets 2017; 17: 213-218

[21] Baloch ZW, Barroeta JE, Walsh J, Gupta PK, Livolsi VA, Langer JE, Mandel SJ. Utility of thyroglobulin measurement in fine-needle aspiration biopsy specimens of lymph nodes in the diagnosis of recurrent thyroid carcinoma. Cytojournal 2008; 31: 1

[22] Cantisani V, Consorti F, Guerrisi A, Guerrisi I, Ricci P, Di Segni M, Mancuso E, Scardella L, Milazzo F, D'Ambrosio F, Antonaci A. Prospective comparative evaluation of quantitative-elastosonography (Q-elastography) and contrast-enhanced ultrasound for the evaluation of thyroid nodules: Preliminary experience. Eur J Radiol 2013; 82: 1892-1898. doi:10.1016/j.ejrad.2013.07.005

[23] Cantisani V, Maceroni P, D'Andrea V, Patrizi G, Di Segni M, De Vito C, Grazhdani H, Isidori AM, Giannetta E, Redler A, Frattaroli F, Giacomelli L, Di Rocco G, Catalano C, D'Ambrosio F. Strain ratio ultrasound elastography increases the accuracy of colour-Doppler ultrasound in the evaluation of Thy-3 nodules. A bi-centre university experience. Eur Radiol 2016; 26: 1441-1449. doi:10.1007/s00330-015-3956-0

[24] Sidhu PS, Brabrand K, Cantisani V, Correas JM, Cui XW, D'Onofrio M, Essig M, Freeman S, Gilja OH, Gritzmann N, Havre RF, Ignee A, Jenssen C, Kabaalioğlu A, Lorentzen T, Mohaupt M, Nicolau C, Nolsøe CP, Nürnberg D, Radzina M, Saftoiu A, Serra C, Spârchez Z, Sporea I, Dietrich CF. EFSUMB Guidelines on Interventional Ultrasound (INVUS), Part II. Diagnostic Ultrasound-Guided Interventional Procedures (Long Version). Ultraschall Med 2015; 36: E15-E35. doi:10.1055/s-0035-1554036

[25] Sidhu PS, Brabrand K, Cantisani V, Correas JM, Cui XW, D'Onofrio M, Essig M, Freeman S, Gilja OH, Gritzmann N, Havre RF, Ignee A, Jenssen C, Kabaalioğlu A, Lorentzen T, Mohaupt M, Nicolau C, Nolsøe CP, Nürnberg D, Radzina M, Saftoiu A, Serra C, Spârchez Z, Sporea I, Dietrich CF. EFSUMB Guidelines on Interventional Ultrasound (INVUS), Part II. Diagnostic Ultrasound-Guided Interventional Procedures (Short Version). Ultraschall Med 2015; 36: 566-580. doi:10.1055/s-0035-1566760

[26] Sidhu PS, Cantisani V, Dietrich CF, Gilja OH, Saftoiu A, Bartels E, Bertolotto M, Calliada F, Clevert DA, Cosgrove D, Deganello A, D'Onofrio M, Drudi FM, Freeman S, Harvey C, Jenssen C, Jung EM, Klauser AS, Lassau N, Meloni MF, Leen E, Nicolau C, Nolsoe C, Piscaglia F, Prada F, Prosch H, Radzina M, Savelli L, Weskott HP, Wijkstra H. The EFSUMB Guidelines and Recommendations for the Clinical Practice of Contrast-Enhanced Ultrasound (CEUS) in Non-Hepatic Applications: Update 2017 (Short Version). Ultraschall Med 2018; 39: 154-180. doi: $10.1055 / \mathrm{s}-0044-101254$ 